\title{
Assessing destructive capacity of impulse loads
}

\author{
Alexander Komarov $^{1 *}$, Nikolay Gromov ${ }^{1}$ and Yulia Sokolova ${ }^{2}$ \\ ${ }^{1}$ Moscow State University of Civil Engineering, 129337, Yaroslavskoye Shosse 26, Moscow, Russia \\ ${ }^{2}$ NOU INEP, 115477, Bekhtereva ul, 13, korp 3, Moscow, Russia
}

\begin{abstract}
The paper gives an overview of the methodology to find dynamic coefficients of impulse loads typical of various emergencies (explosive blast, massive body falling, hydraulic shock, etc.). Criteria are described under which dynamic coefficients are determined by impulse impact alone irrelevant of its form. Correlations are quoted to find dynamic coefficients for impact loads that accompany such emergencies.
\end{abstract}

\section{Introduction}

It is the accepted practice of construction design that non-static loads are reduced to equivalent static loads. Calculations of dynamic impact on building structures use the following methodology. Dynamic load is substituted with its equivalent static load found by this formula [1-3]:

where $P \max _{c}$ - maximum dynamic load value; $K_{d^{-}}$dynamic coefficient equal to maximum value of dynamic function $T(t)$ that describes motion of the structure (its sections shifting) in time.

As is apparent from (2.2.1), to substitute dynamic load with its equivalent load we need to know dynamic factor $K_{d}$.

For example, dynamic coefficient $K d$ for a triangular-shaped load is frequently known from diagrams (Fig. 1) available in many reference manuals on strength calculation of structures, where $\theta$ and $\theta_{1}$ - duration of dynamic load and the time it takes to peak; $\omega_{K}$ frequency of main oscillation pitch in the structure, found using the methods of construction mechanics.

The diagram means that if $\theta_{l}$ tends to zero (saw-tooth load form), then the dynamic coefficient's numeric value approaches 2 . Considering this, designers double any sawtooth load when they do static calculations. However, this approach is wrong for short-term (impulse) loads. This is the issue discussed in this paper.

\footnotetext{
* Corresponding author: KomarovAA @mgsu.ru
} 


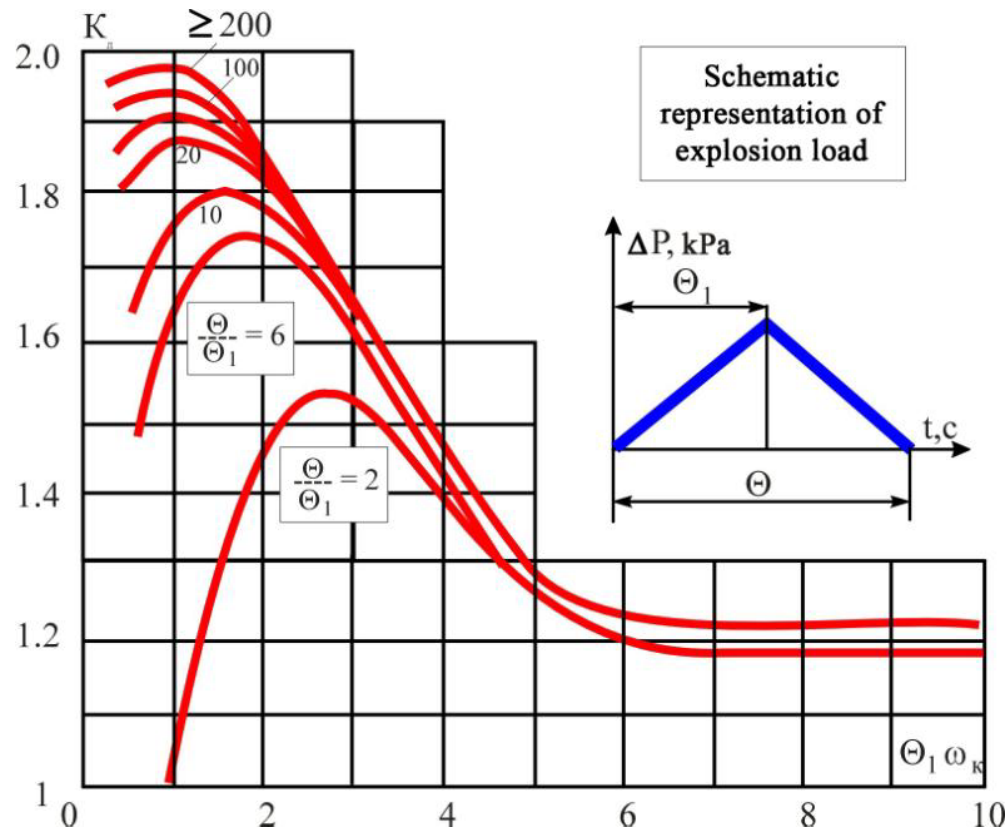

Fig. 1. Diagrams of dynamic coefficient Kd

Emergency situations create momentary loads rather often. Discharge of explosive material or impact of a massive body falling (e.g. transport containers falling in a cooling pool of a nuclear power plant) or hydraulic shock etc. creates loads that last for milliseconds at very high pressures.

Let us examine the dynamic factor methodology for such loads. This discussion will adhere to the approaches accepted in structural dynamics.

We know that the structure's movement at the elastic deformation stage is described by the equation:

$$
\frac{d^{2} T}{d t^{2}}+\omega^{2} \cdot T=\omega^{2} \cdot f(t)
$$

where $\omega$ - circular frequency of the structure's own vibrations круговая частота; $f(t)$ a function to describe changes in time of dimensionless $f(t)=\frac{P(t)}{P_{\max }}$ dynamic load; $T(t)=S(t) / S_{M A K C}-$ relative movement of the structure, or dynamic function; Smax - offset of the structure responding to static load - Pmax.

The solution to equation (1) with zero initial conditions appears as:

$$
\begin{aligned}
& T(t)=\omega \cdot \int_{0}^{t} f(u) \cdot \sin (\omega \cdot(t-u)) \cdot d u=\omega \cdot\left(\sin \omega \cdot t \cdot \int_{0}^{t} f(u) \cdot \cos (\omega \cdot u) \cdot d u-\right. \\
& \left.-\cos \omega \cdot t \cdot \int_{0}^{t} f(u) \cdot \sin (\omega \cdot u) \cdot d u\right) .
\end{aligned}
$$


Numerical integration of expression (3) produces a function of the structure's movement in time responding to force $f(t)$. The maximum value of displacement function $T(t)$ is dynamic coefficient $K_{d}$.

To find the dynamic coefficient we need to know the frequency of the structure's own oscillation pitch - $\omega$, expressed with formula [4]:

$$
\omega=\frac{\alpha}{L^{2}} \cdot \sqrt{\frac{B}{M_{k}}},
$$

where $L$ - structure's span; $B$ - bend rigidity: $B=E \cdot I$, where $E$ - dynamic modulus of elasticity, $I$ - axial moment of inertia, $M_{\kappa}$ - linear mass of structure: $M_{\kappa}=\frac{q}{g}$, where $q-$ linear load from explosion, plus load of the structure's own weight, $\alpha$ - factor quoted from reference literature (e.g., [4]), $g$ - free fall acceleration.

Equation (1) can be solved by solving numerically this system of differential equations of the first order:

$$
\begin{aligned}
& \frac{d U}{d t}=-\omega^{2} \cdot T+\omega^{2} \cdot f(t) \\
& \frac{d T}{d t}=U
\end{aligned}
$$

This method has the following disadvantage. Calculations assume that the process of each element's oscillation uses a certain frequency (typically that of the pitch), although in reality oscillations occur across the entire spectrum of natural frequencies of the elastic element. Moreover, arbitrary limiting conditions can be set with approximation in this method, but to calculate strength of building structures in emergency, when maximum possible loads are assumed as inputs, even though they are unlikely, this approach to calculate $K_{d}$ is justified to an extent.

Equation (1) was integrated for several load types and for different ratios of load duration $\left(\mathrm{T}_{\text {load }}\right)$ to the structure's own oscillation period $\left(\mathrm{T}_{0}\right)$.

Fig. 2 gives values of dynamic coefficients for different ratios of load duration $\left(\mathrm{T}_{\text {load }}\right)$ to the structure's own oscillation period $\left(\mathrm{T}_{0}\right)$, and for five load types. Evidently, the temporal nature of the load is an influence on the dynamic factor only for load duration to oscillation period ratios greater than $0.5^{*} \mathrm{~T}_{0}$. This fact is actually illustrated in Fig. 1, plotted based on rather lengthy loads (relative to the structure's own oscillation period), but not on impulse loads.

Fig. 3 gives values of dynamic coefficients for different load duration to oscillation period ratios, $K=0$ for shock load, and $K=1$ for a load type that only has a buildup phase. Conditionally these can be regarded as extreme forms: shock load and smooth load. 

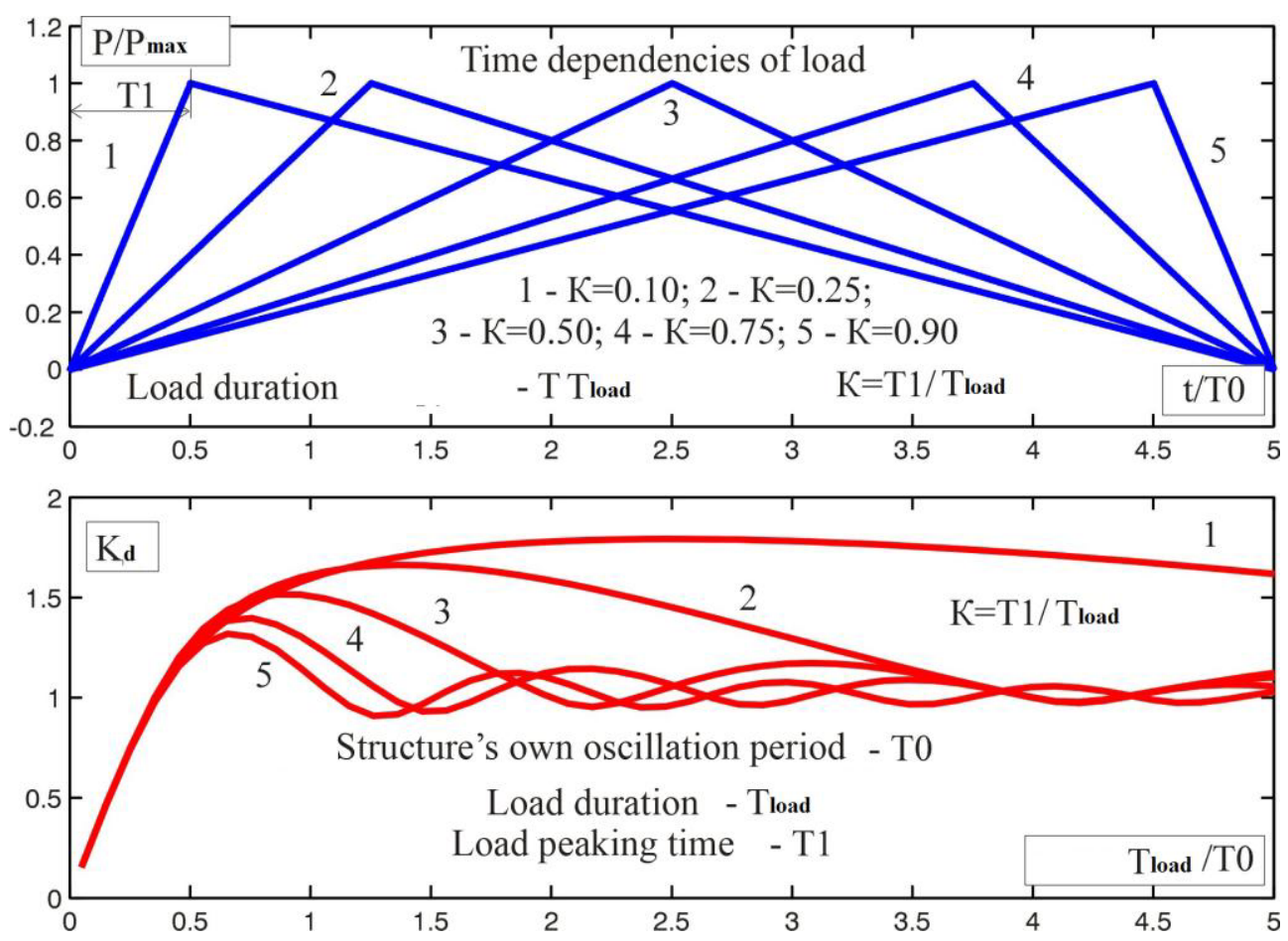

Fig. 2. Dynamic coefficients for five load types
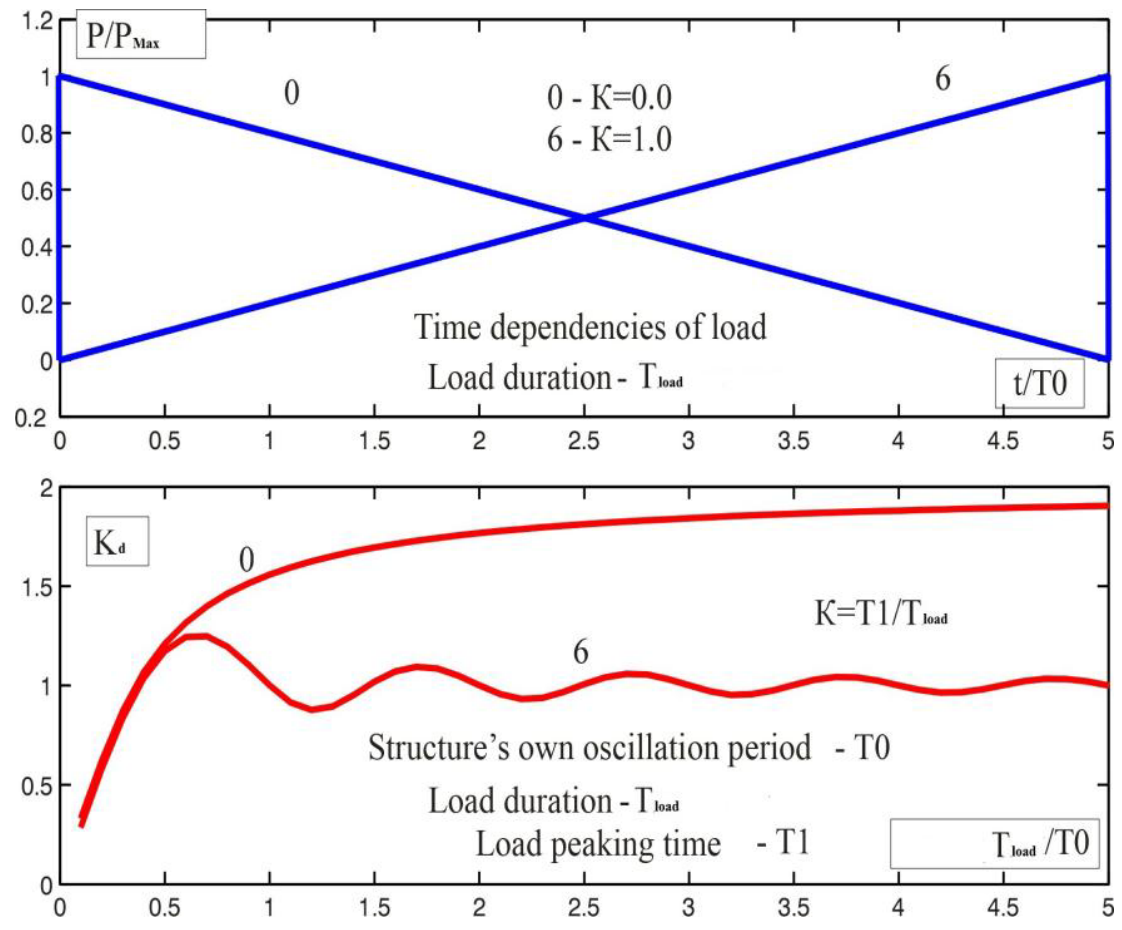

Fig. 3. Dynamic coefficients for two extreme load types 
As stated above (see Fig. 2), for ratios $\mathrm{T}_{\text {НАГРузки }} / \mathrm{T}_{0}<0.5$, the form of load does not affect the numeric values of dynamic coefficients. They are mainly influenced by pressure impulse: $I=\int P(t) d t$. This is seen from the results in Fig. 4 that quotes dynamic coefficients for triangle-shaped loads $\left(I=0.5^{*}\right.$ Pmax*Tlaod $)$ and for rectangle-shaped loads (I=Pmax*Tload).
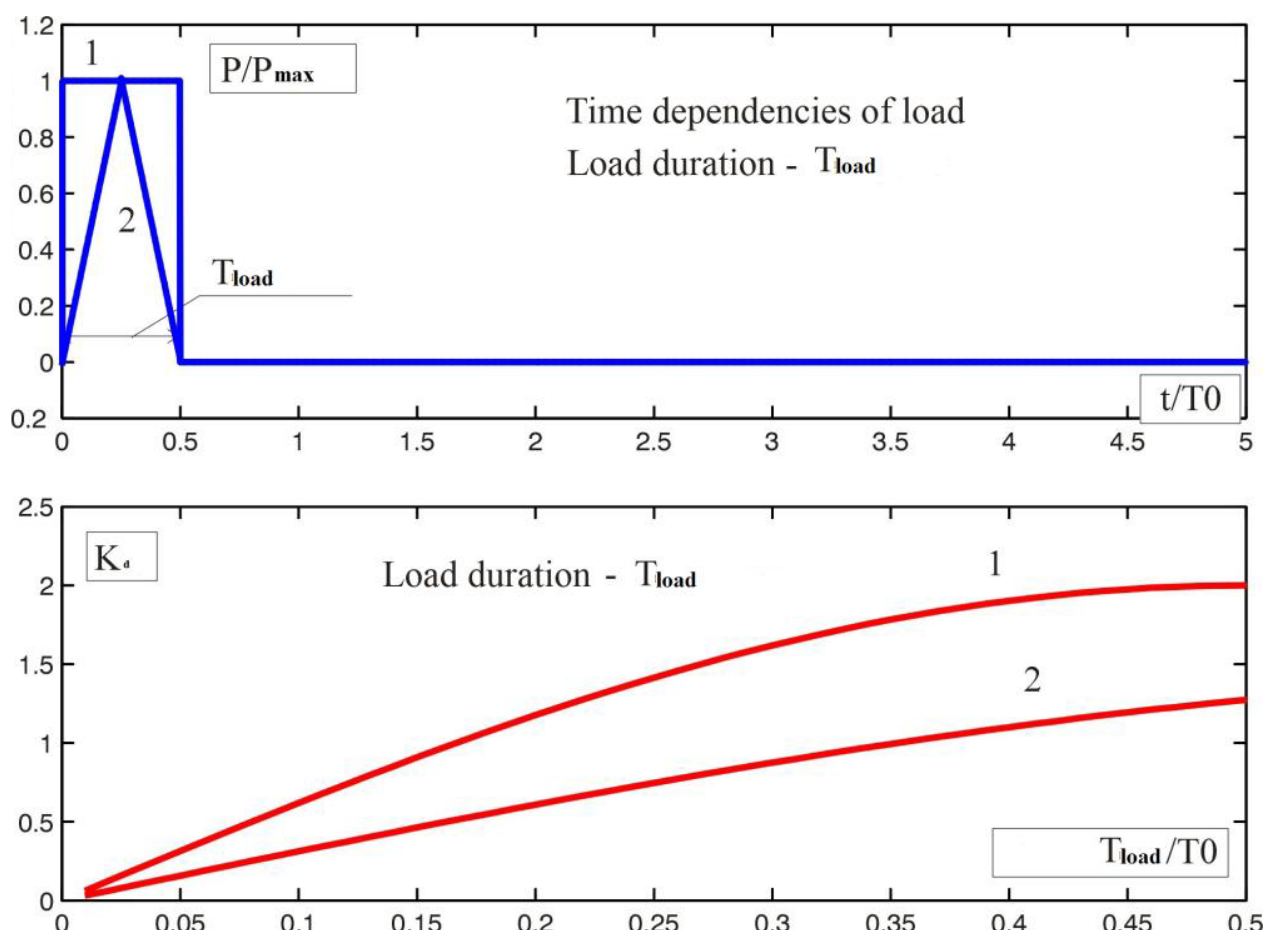

Fig. 4.Dynamic coefficients for ratios $\mathrm{T}_{\text {НАгрузки }} / \mathrm{T}_{0}<0.5$ and for triangle- and rectangle-shaped loads

Calculation demonstrated that dynamic coefficient for brief loads $\left(\mathrm{T}_{\text {load }} / \mathrm{T}_{0}<0.5\right)$ can be approximately found using this formula:

$$
K d=\frac{2 \cdot T_{\text {load }}}{T_{0}} \cdot\left(2-1.5 \cdot\left(1-\frac{I}{P_{\max } \cdot T_{\text {load }}}\right)\right),
$$

where $I$ - pressure impulse $-I=\int P(t) d t$.

For example, in case of a triangle-shaped load $\left(I=0.5^{*}\right.$ Pmax $*$ Tload $)$, the dynamic coefficient will approximately equal:

$$
K d=1.25 \cdot \frac{2 \cdot T_{\text {load }}}{T_{0}}
$$

and for a rectangle-shaped load $(I=$ Pmax $*$ Tload $)$ the dynamic coefficient is: 


$$
K d=2.0 \cdot \frac{2 \cdot T_{\text {load }}}{T_{0}}
$$

\section{Conclusions}

The paper discusses specifics of calculating dynamic coefficients for impulse loads typical of many emergency situations.

Criteria are described under which dynamic coefficients depend only by shock load impulse but not by its shape form.

The paper gives ratios needed to calculate dynamic coefficients for shock loads that accompany emergency situations (discharge of explosive materials, massive body falling, hydraulic shock etc.)

\section{References}

1. N.N. Popov, B.S. Rastorguyev, Dynamic Calculation for Reinforced Concrete Structures (Moscow, Stroyizdat, 1974)

2. B.S. Rastorguyev, Methodological Guidance on Design and Examination of New and Existing Structures in Explosive Production Facilities (Version 1) (Moscow, 1996)

3. SNIP 2.01.07-85. Loads and Impacts. (Supplements. Section 10. Deflection and Displacement).

4. Project Designer's Reference Book. Dynamic Calculation of Special Factors in Construction (Moscow, Stroyizdat, 1981)

5. A.A. Komarov, Forecasting Loads and Estimating Consequences of Their Impact on Buildings and Structure. (Moscow State Construction University (National Research University), Moscow, 2001)

6. A.A. Abrosimov, A.A. Komarov, Oil, Gas and Bus., 6, 58-61 (2002) 